\title{
ANALISIS PERBANDINGAN PEMBIAYAAN MURABAHA PADA BANK BRI SYARIAH, BANK MEGA SYARIAH DAN BANK SYARIAH MANDIRI (Studi Pada Bank Umum Syariah Yang Terdaftar di Indonesia Periode Tahun 2012-2016)
}

\author{
Raja Ria Yusnita \\ Dosen Fakultas Ekonomi Universitas Islam Riau \\ Email : rajaria16@eco.uir.ac.id
}

\begin{abstract}
ABSTRAK
Penelitian ini bertujuan untuk menganalisis perbandingan pembiayaan murabaha pada Bank Umum Syariah. Pembiayaan murabaha diukur dengan Dana Pihak Ketiga (DPK), Non Performing Financing (NPF), Financing to Debt Ratio (FDR) Biaya Operasional dan Pendapatan Operasional (BOPO). Teknik sampling yang digunakan adalah purposive sampling, selama 5 (lima) tahun dan menggunakan IBM SPSS 22 sebagai alat analisis penelitian. Teknik analisis yang digunakan adalah Uji Mann-Whitney. Dari hasil analisis menunjukkan bahwa variabel Dana Pihak Ketiga (DPK) pada Bank Syariah Mandiri, Bank BRI Syariah dan Bank Mega Syariah terdapat perbedaan. Sedangkan variabel Biaya Operasional Pendapatan Operasional (BOPO), Non Performing Financing (NPF) dan Financing to Debt Ratio (FDR) tidak terdapat pembiayaan.
\end{abstract}

Kata Kunci : Dana Pihak Ketiga (DPK), Non Performing Financing (NPF), Financing to Debt Ratio (FDR), Biaya Operasional dan Pendapatan Operasional (BOPO).

\begin{abstract}
This research aims to analyze the comparison of murabaha funding in Bank Umum Syariah. Murabahah funding was measured by Third Party Funds (DPK), Non Performing Financing (NPF), Financing to Debt Ratio (FDR), Operation Cost and Operational Revenue (BOPO). Sampling technique used is purposive sampling, for 5 (five) years and IBM SPSS 22 was used as the research analysis tool. Analysis technique used was Mann-Whitney Test. The results of analysis showed differences of Third Party Fund (DPK) variable in Bank Mandiri Sharia, Bank BRI Sharia and Bank Mega Shariah. While funding was not found for Operation Cost and Operational Revenue (BOPO) variable, Non Performing Financing (NPF) and Financing to Debt Ratio (FDR).
\end{abstract}

Keywords : Third Party Funds (DPK), Non Performing Financing (NPF), Financing to Debt Ratio (FDR), Operation Cost and Operational Revenue (BOPO) 


\section{PENDAHULUAN}

Bank merupakan salah satu urat nadi perekonomian sebuah negara. Selain itu, bank juga merupakan lembaga kepercayaan yang berfungsi sebagai lembaga intermediasi, membantu kelancaran sistem pembayaran, dan yang tidak kalah pentingnya adalah lembaga yang menjadi sarana dalam pelaksanaan kebijakan pemerintah, yaitu kebijakan moneter.

Berdasarkan fungsi-fungsi tersebut, maka keberadaan bank yang sehat, baik secara individu maupun secara keseluruhan sebagai suatu sistem, merupakan prasyarat bagi suatu perekonomian yang sehat (www.bi.go.id). terdapat dua jenis bank yang ada di Indonesia, diantaranya bank konvensional dan bank syariah. Perbedaan bank konvensional dengan bank yang berprinsip syariah yang paling pokok adalah prinsip operasi bank itu sendiri.

Bank konvensional menggunakan sistem bunga yang rentan terhadap kondisi ekonomi negara, sedangkan bank yang berprinsip syari ah tidak membebankan bunga melainkan mengajak partisipasi dalam bidang usaha yang didanai. Prinsip bagi hasil merupakan karakteristik dasar perbankan syariah, prinsip syariah terbukti mampu bertahan dan memiliki kinerja yang lebih baik serta konsisten dalam menjalankan fungsi intermediasinya.

Bank syariah memiliki tujuan umum menyediakan pelayanan jasa keuangan sesuai dengan prinsip syariah dan sekaligus mempromosikan, mendorong dan mengembangkan penerapan prinsip dan nilai-nilai syariah dalam transaksi keuangan, perbankan dan kegiatan ekonomi pada umumnya, sehingga diharapkan kehadiran bank syariah sebagai salah satu solusi alternatif (bank alternatif) dapat lebih adil dan dapat memberikan perlindungan bagi keadaan perekonomian nasional, serta dapat berupaya untuk mendorong meningkatkan penyaluran pembiayaan pada sektor riil.

Pembiayaan adalah salah satu produk usaha bank syariah yang mampu menghasilkan keuntungan Menurut Sumiyanto (2008), "Pembiayaan adalah aktifitas menyalurkan dana yang terkumpul kepada anggota pengguna dana, memilih jenis usaha yang akan dibiayai agar diperoleh jenis usaha yang produktif, menguntungkan dan dikelola oleh anggota yang jujur dan bertanggung jawab".

Berdasarkan hasil Statistik Perbankan Indonesia 2013, pembiayaan yang disalurkan perbankan syariah hampir $80 \%$ menggunakan skema murabaha dengan prinsip jual beli. Dominasi produk pembiayaan dengan prinsip jual beli ini disebabkan oleh resiko yang dihadapi bank syariah lebih kecil dibandingkan dengan resiko pada skema pembiayaan bagi hasil seperti mudharaba dan musyarakah.

Keberadaan Bank Syariah dalam sistem perbankan Indonesia sebenarnya telah dikembangkan semenjak tahun 1992. Seiring dengan lahirnya undangundang No. 7 tahun 1992, tentang perbankan. Kendati masih tertuang secara implisit dengan istilah Bank bagi hasil. Kemudian diiringi oleh peraturan pemerintah No. 72 tahun 1992 tentang Bank berdasarkan bagi hasil. Sebagai dasar operasionalnya. Sesudah UU No. 7 tersebut diganti menjadi Undang-undang No. 10 tahun 1998 tentang layanan perbankan, dimana pada Undang-undang ini mulai diperkenalkan istilah Dual Banking Sistem. Menurut Achyar Ilyas (Mantan Deputi Gubernur Bank Indonesia), pemerintah indonesia senantiasa berupaya memperbaiki perundangan yang ada agar persoalan perbankan Syariah semakin memiliki aturan yang jelas seperti Undang-undang 
No. 23 tahun 1999, tentang Bank Indonesia (selanjutnya diamandemen dengan UU No. 3 tahun 2004), sehingga Bank Indonesia sendiri sebagai Bank Sentral di Indonesia bisa menerapkan kebijaksanaan moneter (keuangan) berdasarkan kepada prinsip-prinsip Syariah dan dapat mempengaruhi liquiditas perekonomian melalui Bankbank Syariah. Atas dasar itulah lahir Undang-undang No. 21 tahun 2008, tentang perbankan Syariah yang telah rinci dan khusus mengatur sistem perbankan Syariah di Indonesia.

Secara umum tujuan utama Bank Syariah ialah mendorong dan mempercepat kemajuan ekonomi suatu masyarakat atau bangsa, dengan melakukan aktivitas perbankan, keuangan, komersial, dan investasi sesuai dengan asas Islam. Upaya ini harus didasari dengan: (a) Larangan atas bunga pada setiap transaksi; (b) Asas kerekanan (partnership) pada semua aktivitas bisnis yang berdasarkan kesetaraan, keadilan dan kejujuran; (c) Hanya mencari keuntungan yang sah dan halal semata-mata; (d) Pembinaan keuangan kepada masyarakat; (e) Mengembangkan persaingan yang sehat; (f) Menghidupkan lembaga zakat; (g) dan membentuk jaringan kerja sama (networking) dengan lembaga keuangan Islam lainnya.

\section{TINJAUAN PUSTAKA \\ Teori Perbandingan}

Perbandingan atau metode komparatif, suatu metode dalam ilmu sosial yang bertujuan menguji dua atau lebih gejala sosial untuk menghasilkan persamaan dan atau perbedaan dalam hal yang diteliti, sesuai dengan masalah dan tujuan peneliti. Teori evolusi organik merupakan salah satu metode perbandingan utama dalam ilmu-ilmu biologi. Metode perbandigan dinyatakan sebagai penemuan terbesar dalam abad ke-19 oleh Max Muller dan E.A.
Freeman. Perbandingan terdiri dari dua macam, yaitu:

Perbandingan Senilai, Perbandingan dikatakan sebagai perbandingan senilai adalah jika dua perbandingan tersebut memiliki harga yang sama.

Perbandingan Berbalik Nilai, Perbandingan dikatakan berbalik nilai jika dua perbandingan tersebut selalu tetap (Konstan) walaupun perbandingannya dibalik.

\section{Teori Pembiayaan}

Berdasarkan Undang-Undang Republik Indonesia Nomor 10 Tahun 1998, Bank adalah badan usaha yang menghimpun dana dari masyarakat dalam bentuk simpanan dan menyalurkan kepada masyarakat dalam bentuk kredit dan atau bentuk-bentuk lainnya dalam rangka meningkatkan taraf hidup rakyat banyak.

Pembiayaan merupakan kegiatan Bank Syariah dalam menyalurkan dananya kepada pihak nasabah yang membutuhkan dana. Pembiayaan sangat bermanfaat bagi Bank Syariah, nasabah, dan pemerintah. Pembiayaan memberikan hasil yang besar diantara penyaluran dana lainnya yang dilakukan oleh Bank Syariah. Sebelum menyalurkan dana melalui pembiayaaan, Bank Syariah perlu melakukan analisis pembiayaan yang mendalam, sehingga kerugian dapat dihadiri (Ismail, 2011). Tentang Perbankan Syariah, Pembiayaan adalah penyedia dana atau tagihan yang dipersamakan dengan itu berupa: (a) Transaksi bagi hasil dalam bentuk Mudharaba dan Musyarakah, (b) Transaksi sewa-menyewa dalam bentuk ijarah atau sewa beli dalam bentuk ijarah muntahiya bittamlik, (c) Transaksi jual beli dalam bentuk piutang Murabaha, Salam, dan istisnha, (d) Transaksi pinjam meminjam dalam bentuk piutang qardh, dan (e) Transaksi sewa-menyewa jasa dalam bentuk ijarah untuk transaksi multijasa. 
METODE PENELITIAN

Variabel Penelitian dan Definisi

Operasional

Dapat dikatakan bahwa variabel adalah suatu sifat yang dapat dimiliki bermacam nilai (harga). Apabila suatu variabel hanya mempunyai suatu nilai saja, maka variabel tersebut disebut konstanta. Suatu variabel disebut diskrit apabila cacah nilainya berhingga atau nilai-nilainya dapat didaftar. Apabila cacah nilainya tidak terhingga dan nilainilainya tidak dapat didaftar maka variabel tersebut disebut kontinu.

Tabel 1. Operasional Variabel Penelitian

\begin{tabular}{|c|c|c|c|}
\hline No & Variabel & Defin isi & Indikator \\
\hline 1 & $\begin{array}{l}\text { Dana Pihak } \\
\text { Ketiga }\end{array}$ & $\begin{array}{l}\text { Dana yang dipercayakan oleh Nasabah } \\
\text { kepada Bank Syariah dan/ UUS } \\
\text { berdasarkan akad Wadiah atau akad } \\
\text { lain yang tidak bertentangan dengan } \\
\text { prinsip Syariah dalam bentuk Giro, } \\
\text { Tabungan dan bentuk lainnya. }\end{array}$ & Tabungan + Deposito + Giro \\
\hline 2 & BOPO & $\begin{array}{l}\text { Merupakan rasio yang menggambarkan } \\
\text { efisiensi perbankan dalam melakukan } \\
\text { kegiatannya. Belanja operasional } \\
\text { adalah biaya bunga yang diberikan pada } \\
\text { nasabah sedangkan pendapatan } \\
\text { operasional adalah bunga yang } \\
\text { didapatkan dari nasabah. }\end{array}$ & BOPO $\frac{\text { Belan ja Operasional }}{\text { Pendapatan Operasional }} \times 100$ \\
\hline 3 & $\begin{array}{l}\text { Non } \\
\text { Performing } \\
\text { Financing }\end{array}$ & $\begin{array}{l}\text { Merupakan rasio pembiayaan yang } \\
\text { bermasalah di suatu bank, apabila } \\
\text { pembiayaan bermasalah meningkat } \\
\text { maka resiko terjadinya penurunan } \\
\text { profitabilitas semakin besar. }\end{array}$ & 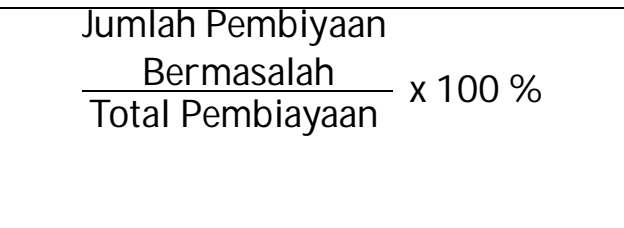 \\
\hline 4 & $\begin{array}{l}\text { Financing } \\
\text { to Deposit } \\
\text { Ratio }\end{array}$ & $\begin{array}{l}\text { Mengukur kemampuan bank syariah } \\
\text { dalam memenuhi semua kewajiban } \\
\text { jangka pendeknya pada saat jatuh } \\
\text { tempo. }\end{array}$ & $\begin{array}{l}\text { Jumlah Pembiayaan yang } \\
\frac{\text { disalurkankan }}{\text { Total Deposit }} \times 100 \%\end{array}$ \\
\hline
\end{tabular}

Populasi dan Sampel

Populasi merupakan objek yang berada pada suatu wilayah dan memenuhi syarat tertentu yang berkaitan dengan masalah dalam penelitian. Populasi adalah jumlah keseluruhan objek (satuan-satuan atau individu-individu) yang memiliki ciri atau karakteristik yang sama. Populasi yang digunakan dalam penelitian ini adalah seluruh Bank Umum Syariah (BUS) yang ada di Indonesia periode 2012-2016 yang berjumlah 13 Bank.

Tabel 2. Daftar Bank Umum Syariah (BUS) sebagai Populasi Penelitian

\begin{tabular}{cll}
\hline No & Nama Bank & Kode \\
\hline 1 & PT. Bank Aceh Syariah & BAS \\
\hline 2 & PT. Bank Muamalat Indonesia & BMI \\
\hline 3 & PT. Bank Victoria Syariah & BVS \\
\hline
\end{tabular}




\begin{tabular}{cll}
\hline 4 & PT. Bank BRI Syariah & BRIS \\
\hline 5 & PT. Bank Jabar Banten Syariah & BJBS \\
\hline 6 & PT. Bank BNI Syariah & BNIS \\
\hline 7 & PT. Bank Syariah Mandiri & BSM \\
\hline 8 & PT. Bank Mega Syariah & BMS \\
\hline 9 & PT. Bank Panin Syariah & BPS \\
\hline 10 & PT. Bank Syariah Bukopin & BSB \\
\hline 11 & PT. BCA Syariah & BCAS \\
\hline 12 & PT. Maybank Syariah Indonesia & MSI \\
\hline 13 & PT. Bank Tabungan Pensiunan Nasional Syariah & BTPNS \\
\hline
\end{tabular}

(Sumber: www.idx.co.id, 2016)

Selanjutnya, yaitu menentukan sampel. Sampel adalah bagian dari populasi yang dapat mewakili populasi. Sampel dari penelitian ini adalah Bank BRI Syariah, Bank Mega Syariah dan Bank Syariah yang berjumlah 3 Bank. Pengambilan 3 Bank ini dilihat berdasarkan asset pada tahun 2016 dengan kriteria asset tertinggi (Bank Syariah Mandiri) sebesar 23.11, sedang (Bank BRI Syariah) sebesar 17.46, terendah (Bank Mega Syariah) sebesar 5.6 (Maybank, 2016). Agar sampel dapat memberikan informasi yang mewakili populasi, dibutuhkan metode pemilihan sampel yang tepat (Mudrajad Kuncoro, 2009:128).

Teknik pengambilan sampel yang digunakan dalam penelitian ini dengan menggunakan teknik purposive sampling. Menurut Sugiyono (2011), purposive sampling adalah teknik penentuan sampel dengan pertimbangan tertentu. Maka sampel pada penelitian ini yaitu laporan keuangan bank umum syariah yang terdaftar di Bank Indonesia periode 2012-2016 dan berjumlah 3 Bank.

Tabel 3. Daftar Bank Umum Syariah (BUS) sebagai Sampel Penelitian

\begin{tabular}{cll}
\hline No & \multicolumn{1}{c}{ Nama Perbankan } & Kode \\
\hline $\mathbf{1}$ & PT. Bank BRI Syariah & BRIS \\
\hline $\mathbf{2}$ & PT. Bank Syariah Mandiri & BSM \\
\hline $\mathbf{3}$ & PT. Bank Mega Syariah & BMS \\
\hline \multicolumn{3}{c}{ (Sumber: $w w w . i d x . c o . i d$, 2016) }
\end{tabular}

METODE ANALISIS DATA Uji Deskriptif

Statistik deskriptif yang digunakan untuk menganalisis data yang dilihat dari nilai rata-rata (mean), Standar Deviasi, Varians, Maximum, Minimum, Sum, Range, Kurtosis dan Skewness $\mathrm{s}$ data merupakan syarat pokok yang harus dipenuhi dalam analisis parametrik. Normalitas data merupakan
(Kemencengan Distribusi) dengan cara mendeskripsikan data yang telah terkumpul sebagaimana adanya tanpa bermaksud membuat kesimpulan yang berlaku untuk umum atau generalisasi.

\section{Uji Normalitas}

\section{Normalita}

hal yang penting karena dengan data yang berdistribusi normal, maka data tersebut dapat mewakili populasi. 
Berikut akan dibahas uji normalitas dengan metode uji liliefors.

1. Prosedur uji normalitas

Prosedur uji normalitas sebagi berikut:

Ho : Berdistribusi normal

H1 : Tidak berdistribusi normal

2. Kriteria Pengujian

Jika signifikan > 0,05 maka Ho diterima

Jika signifikan $<0,05$ maka Ho ditolak

Apabila terdapat data yang tidak berdistribusi normal maka dapat didistribusikan dari parametrik ke nonparametrik, karena non-parametrik test tanpa persyaratan normalitas data atau homogenitas varian tidak seperti pada independent test.

\section{Uji Mann-Whitney Test}

Satu dari banyak teknik nonparametrik yang sering digunakan adalah mann-whitney test atau sering disebut juga Wilcoxon rank-sum test merupakan prosedur non-parametrik yang digunakan untuk membandingkan dua sampel yang independen dan tidak berhubungan.

Mann-Whitney test dapat digunakan tanpa persyaratan normalitas data atau homogenitas varian tidak seperti pada independen t-test. Namun, asumsi yang harus dipenuhi oleh MannWhitney test adalah data dua sampel yang digunakan harus independen. Uji Mann-Whitney digunakan dalam penelitian ini perkuat dari jurnal internasional yaitu M. Selvakumar and V. Sathyalakshmil.

Secara matematis Mann-Whitney test dapat ditulis sebagai berikut:

$\mathrm{U}_{\mathrm{i}}=n 1 n 2+\frac{n i(n i+1)}{2}-\sum R i$

$\mathrm{n}_{1} \mathrm{n}_{2}=\mathrm{U}_{1+} \mathrm{U}_{2}$

Dimana $\mathrm{n}_{1} \mathrm{n}_{2}$ merupakan sampel group satu dan dua; $\sum \mathrm{R}_{\mathrm{i}}$ jumlah dari rank. Mann-Whitney test dapat digunakan ketika jumlah sampel kedua group $\left(\mathrm{n}_{1}\right.$ dan $\left.\mathrm{n}_{2}\right)$ adalah sama dengan 20 atau U kurang dari itu, jika sampel yang digunakan lebih dari 20, maka kita harus menggunakan z-statistik yang dihitung dengan rumus :

$$
Z=\frac{U+c-E(U)}{\sigma \mathrm{u}}=\frac{(\mathrm{U}+\mathrm{c})-\mathrm{n} 1 \mathrm{n} 2 / 2}{\sqrt{(\mathrm{n} 1 \mathrm{n} 2)(\mathrm{n} 1+\mathrm{n} 2+1) / 12}}
$$

Dimana U merupakan MannWhitney test; $\mathrm{n}_{1}$ dan $\mathrm{n}_{2}$ merupakan jumlah sampel untuk group satu dan dua; $\mathrm{c}=0.05$. pengambilan keputusan untuk z-test sama dengan : hipotesis null ditolak jika nilai $\mathrm{z}$ dibawah critical value, dan sebaliknya jika diatas critical value maka kita tidak dapat menolak hipotesis null. Karena dari nilai U didefinisikan, maka perhitungan $\mathrm{z}$ akan selalu bernilai negatif jika menggunakan one-tailed atau two-tailed. Sehingga untuk menguji signifikan, menggunakan nilai absolute dari z-statistik.

Untuk menguji hipotesis statistik dari Mann-Whitney test, kita gunakan:

Ho: Distribusi populasi dua group identik/sama

H1: Distribusi Populasi dua Group berbeda

Untuk menguji hipotesis digunakan level signifikansi 0.05 , jika didapat probabilitas signifikan $<0.05$, maka dapat disimpulkan distribusi populasi dua group tidak identik/berbeda atau tidak sama. Dan sebaliknya, jika didapat probabilitas signifikansi $>0.05$, maka dapat disimpulkan distribusi populasi dua group identik atau sama.

Untuk menghitung effect size $r$ Mann-Whitney test, digunakan nilai zscore yang dihasilkan dibagi dengan akar kuadrat dari total jumlah sampel di dalam studi. Secara sistematis dapat dituliskan: 
$r=\frac{\mathrm{Z}}{\sqrt{\mathrm{N}}}$

Dimana $\mathrm{Z}$ merupakan nilai absolute $\mathrm{Z}$-score dan $\mathrm{N}$ merupakan total jumlah sampel berdasarkan pada $\mathrm{z}$ statistik. Nilai effect size akan berkisar dari 0 sampai 1. Cohen (1988) mendefenisikan nilai effect size small $\geq$ 0.10 , medium $\geq 0.30$ dan large $\geq 0.50$. Untuk melaporkan hasil analisis MannWhitney test, hanya butuh melaporkan signifikansi $U$ test dan juga melaporkan nilai effect size.

Tabel 4. One-Sample Kolmogorov-Smirnov Test

\begin{tabular}{llllll}
\hline & & BOPO & DPK & NPF & FDR \\
\hline $\mathrm{N}$ & & 15 & 15 & 15 & 15 \\
\hline \multirow{2}{*}{$\begin{array}{l}\text { Normal } \\
\text { Parameters }\end{array}$} & Mean & 9064.2667 & 7621.0749 & 421.0000 & 9068.5333 \\
\cline { 2 - 6 } & $\begin{array}{l}\text { Std. } \\
\text { Deviation }\end{array}$ & 789.34851 & 7600.76879 & 118.91173 & 745.14868 \\
\hline \multirow{2}{*}{$\begin{array}{l}\text { Most Extreme } \\
\text { Differences }\end{array}$} & Absolute & .155 & .173 & .142 & .174 \\
\cline { 2 - 6 } & Positive & .124 & .173 & .142 & .143 \\
\cline { 2 - 6 } & Negative & -.155 & -.160 & -.098 & -.174 \\
\hline Test Statistic & & .155 & .173 & .142 & .174 \\
\hline Asymp. Sig. (2-tailed) & $.200^{\mathrm{c,d}}$ & $.200^{\mathrm{c,d}}$ & $.200^{\mathrm{c,d}}$ & $.200^{\mathrm{c,d}}$ \\
\hline
\end{tabular}

Berdasarkan tabel diatas dapat dilihat bahwa Sig. (2-tailed) rasio Biaya Operasional Pendapatan Operasional (BOPO), Dana Pihak Ketiga (DPK), Non Performing Financing (NPF) dan Financing to Debt Ratio (FDR) > 0.05 ini menunjukkan data dari rasio Biaya Operasional Pendapatan Operasional (BOPO), Dana Pihak Ketiga (DPK), Non Performing Financing (NPF) dan Financing to Debt Ratio (FDR) normal

\section{HASIL PENELITIAN DAN PEMBAHASAN}

\section{Uji Normalitas}

Uji Normalitas disini dimaksudkan untuk mengetahui normal atau tidaknya data dari variabel-variabel yang digunakan dalam penelitian yaitu variabel Biaya Operasional Pendapatan Operasional (BOPO), Dana Pihak Ketiga (DPK), Non Performing Financing (NPF) dan Financing to Debt Ratio (FDR). atau memenuhi asumsi klasik normalitas.

\section{Statistik Deskriptif}

Statistik deskriptif ini di maksudkan untuk menggambarkan variabel-variabel yang digunakan dalam penelitian yaitu variabel ukuran (BOPO) Biaya Operasional Pendapatan Operasional, (DPK) dana pihak ketiga, (NPF) Non Performing Financing, dan (FDR) Financing to Debt Ratio.

Tabel 5. Descriptive Statistics Bank Syariah Mandiri

\begin{tabular}{lrrrrr}
\hline & N & \multicolumn{1}{c}{ Minimum } & Maximum & \multicolumn{1}{c}{ Mean } & Std. Deviation \\
\hline BOPO & 5 & 7300.00 & 9846.00 & 8887.8000 & 1036.50962 \\
\hline DPK & 5 & 47.41 & 69.95 & 59.1508 & 8.23030 \\
\hline NPF & 5 & 282.00 & 684.00 & 499.2000 & 155.96538 \\
\hline FDR & 5 & 7919.00 & 9440.00 & 8541.6000 & 627.78324 \\
\hline
\end{tabular}


Valid N (listwise) $\quad 5$

Pada tabel 5. menjelaskan bahwa rata-rata BOPO (Biaya Operasional Pendapatan Operasional) lebih tinggi dari rasio Dana Pihak ketiga (DPK), Non Financing (NPF) dan Financing to Debt Ratio (FDR). Berarti Bank Syariah Mandiri lebih efisien terhadap jumlah permintaan pembiayaan Syariah.

Performing

Tabel 6. Descriptive Statistics Bank BRI Syariah

\begin{tabular}{lcrrrr}
\hline & N & \multicolumn{1}{c}{ Minimum } & Maximum & \multicolumn{1}{c}{ Mean } & Std. Deviation \\
\hline BOPO & 5 & 9042.00 & 9977.00 & 9332.4000 & 381.55445 \\
\hline DPK & 5 & 11014.25 & 22045.10 & 16793.3260 & 4507.04210 \\
\hline NPF & 5 & 300.00 & 486.00 & 421.8000 & 74.00135 \\
\hline FDR & 5 & 8189.00 & 10270.00 & 9272.2000 & 947.96213 \\
\hline Valid N (listwise) & 5 & & & & \\
\hline
\end{tabular}

Pada tabel 6. menjelaskan bahwa rata-rata BOPO (Biaya Operasional Pendapatan Operasional) lebih tinggi dari rasio Dana Pihak Ketiga (DPK), Non Performing Financing (NPF) dan
Financing to Debt Ratio (FDR). Ini menunjukkan bahwa Bank BRI Syariah lebih efisien dalam melakukan pembiayaan syariah.

Tabel 7. Descriptive Statistics Bank Mega Syariah

\begin{tabular}{lcrrrr}
\hline & N & Minimum & Maximum & \multicolumn{1}{c}{ Mean } & \multicolumn{1}{l}{ Std. Deviation } \\
\hline BOPO & 5 & 7728.00 & 9951.00 & 8972.6000 & 906.37426 \\
\hline DPK & 5 & 4354.55 & 7736.25 & 6010.7480 & 1415.92968 \\
\hline NPF & 5 & 267.00 & 426.00 & 342.0000 & 65.13448 \\
\hline FDR & 5 & 8888.00 & 9849.00 & 9391.8000 & 347.94928 \\
\hline Valid N (listwise) & 5 & & & &
\end{tabular}

Pada tabel 7. menjelaskan bahwa rata-rata Financing to Debt Ratio (FDR) lebih tinggi dari rasio Biaya Operasional Pendapatan Operasional (BOPO), Dana Pihak Ketiga (DPK), dan Non Performing Financing (NPF). Ini menunjukkan bahwa kemampuan Bank Mega Syariah dalam memenuhi semua kewajiban jangka pendeknya pada saat jatuh tempo sangat bagus.

\section{Uji Mann-Whitney}

Uji Mann-Whitney disini untuk mengetahui ada tidak adanya perbandingan pembiayaan murabaha pada Bank Syariah Mandiri, Bank BRI Syariah dan Bank Mega Syariah dengan membandingakan ketiga (3) Bank tersebut.

Tabel 8. Test Statistics $^{a}$ Bank Syariah Mandiri

\begin{tabular}{lr}
\hline & \multicolumn{2}{c}{ BOPO } \\
\hline Mann-Whitney U & 11.000 \\
\hline Wilcoxon W & 26.000 \\
\hline Z & -.313 \\
\hline
\end{tabular}


2018, Jurnal Tabarru' : Islamic Banking and Finance 1 (1) : 23 - 36

\begin{tabular}{ll} 
Asymp. Sig. (2-tailed) & .754 \\
\hline Exact Sig. [2*(1-tailed Sig.)] & $.841^{\mathrm{b}}$ \\
\hline
\end{tabular}

Berdasarkan tabel variabel Biaya Operasional Pendapatan Operasional (BOPO) diatas dapat dilihat hasil analisis Mann-Whitney test Bank Syariah
Mandiri diperoleh nilai probabilitas signifikansi $0.754>0.05$ sehingga dapat disimpulkan bahwa tidak terdapat perbedaan.

Tabel 9. Test Statistics ${ }^{a}$ Bank BRI Syariah

\begin{tabular}{lr}
\hline & BOPO \\
\hline Mann-Whitney U & 12.000 \\
\hline Wilcoxon W & 27.000 \\
\hline$Z$ & -.104 \\
\hline Asymp. Sig. (2-tailed) & .917 \\
\hline $\begin{array}{l}\text { Exact Sig. [2*(1-tailed } \\
\text { Sig.)] }\end{array}$ & $1.000^{\mathrm{b}}$ \\
\hline
\end{tabular}

Berdasarkan tabel variabel Biaya Operasional Pendapatan Operasional (BOPO) diatas dapat dilihat hasil analisis Mann-Whitney test Bank BRI
Syariah diperoleh nilai probabilitas signifikansi $0.917>0.05$ sehingga dapat disimpulkan bahwa tidak terdapat perbedaan.

\section{Tabel 10. Test Statistics ${ }^{\text {a }}$ Bank Mega Syariah}

\begin{tabular}{lr}
\hline & BOPO \\
\hline Mann-Whitney U & 8.000 \\
\hline Wilcoxon W & 23.000 \\
\hline$Z$ & -.940 \\
\hline Asymp. Sig. (2-tailed) & .347 \\
\hline Exact Sig. [2*(1-tailed & $.421^{\mathrm{b}}$ \\
Sig.)] & \\
\hline
\end{tabular}

Berdasarkan tabel variabel Biaya Operasional Pendapatan Operasional (BOPO) diatas dapat dilihat hasil analisis Mann-Whitney test Bank Mega Syariah diperoleh nilai probabilitas signifikansi $0.347>0.05$ sehingga dapat disimpulkan bahwa tidak terdapat perbedaan.

Tabel 11. Test Statistics ${ }^{a}$ Bank Syariah Mandiri

\begin{tabular}{lr}
\hline & DPK \\
\hline Mann-Whitney U & .000 \\
\hline Wilcoxon W & 15.000 \\
\hline Z & -2.611 \\
\hline Asymp. Sig. (2-tailed) & .009 \\
\hline
\end{tabular}


2018, Jurnal Tabarru' : Islamic Banking and Finance 1 (1) : 23 - 36

\begin{tabular}{ll}
\hline Exact Sig. [2*(1-tailed & $.008^{\mathrm{b}}$ \\
Sig.)]
\end{tabular}

Berdasarkan tabel variabel Dana Pihak Ketiga (DPK) diatas dapat dilihat hasil analisis Mann-Whitney test Bank Syariah Mandiri diperoleh nilai probabilitas signifikansi $0.009<0.05$ sehingga dapat disimpulkan bahwa terdapat perbedaan.

Tabel 12. Test Statistics ${ }^{a}$ Bank BRI Syariah

\begin{tabular}{lr}
\hline & DPK \\
\hline Mann-Whitney U & .000 \\
\hline Wilcoxon W & 15.000 \\
\hline$Z$ & -2.611 \\
\hline Asymp. Sig. (2-tailed) & .009 \\
\hline Exact Sig. [2*(1-tailed & $.008^{\mathrm{b}}$ \\
Sig.)] & \\
\hline
\end{tabular}

Berdasarkan tabel variabel Dana Pihak Ketiga (DPK) diatas dapat dilihat hasil analisis Mann-Whitney test Bank
BRI Syariah diperoleh nilai probabilitas signifikansi $0.009<0.05$ sehingga dapat disimpulkan bahwa terdapat perbedaan.

\section{Tabel 13. Test Statistics ${ }^{a}$ Bank Mega Syariah}

\begin{tabular}{lr}
\hline & DPK \\
\hline Mann-Whitney U & .000 \\
\hline Wilcoxon W & 15.000 \\
\hline$Z$ & -2.611 \\
\hline Asymp. Sig. (2-tailed) & .009 \\
\hline Exact Sig. [2*(1-tailed & $.008^{\mathrm{b}}$ \\
Sig.)] & \\
\hline
\end{tabular}

Berdasarkan tabel variabel Dana Pihak Ketiga (DPK) diatas dapat dilihat hasil analisis Mann-Whitney test Bank Mega Syariah diperoleh nilai probabilitas signifikansi $0.009<0.05$ sehingga dapat disimpulkan bahwa terdapat perbedaan.

Tabel 14. Test Statistics ${ }^{a}$ Bank Syariah Mandiri

\begin{tabular}{lr}
\hline & NPF \\
\hline Mann-Whitney U & 4.000 \\
\hline Wilcoxon W & 19.000 \\
\hline Z & -1.776 \\
\hline Asymp. Sig. (2-tailed) & .076 \\
\hline
\end{tabular}


2018, Jurnal Tabarru' : Islamic Banking and Finance 1 (1) : 23 - 36

\begin{tabular}{l}
\hline Exact Sig. [2*(1-tailed $\quad .095^{\mathrm{b}}$ \\
Sig.)]
\end{tabular}

Berdasarkan tabel variabel Non diperoleh nilai probabilitas signifikansi Performing Financing (NPF) diatas $0.076>0.05$ sehingga dapat disimpulkan dapat dilihat hasil analisis Mann- bahwa tidak terdapat perbedaan.

Whitney test Bank Syariah Mandiri

Tabel 15. Test Statistics ${ }^{a}$ Bank BRI Syariah

\begin{tabular}{lr}
\hline & NPF \\
\hline Mann-Whitney U & 8.000 \\
\hline Wilcoxon W & 23.000 \\
\hline$Z$ & -.940 \\
\hline Asymp. Sig. (2-tailed) & .347 \\
\hline Exact Sig. [2*(1-tailed & $.421^{\mathrm{b}}$ \\
Sig.)] & \\
\hline
\end{tabular}

Berdasarkan tabel variabel Non

diperoleh nilai probabilitas signifikansi Performance Financing (NPF) diatas $0.347>0.05$ sehingga dapat disimpulkan dapat dilihat hasil analisis Mann- bahwa tidak terdapat perbedaan.

Whitney test Bank BRI Syariah

Tabel 16. Test Statistics ${ }^{a}$ Bank Mega Syariah

\begin{tabular}{lr}
\hline & NPF \\
\hline Mann-Whitney U & 4.000 \\
\hline Wilcoxon W & 19.000 \\
\hline$Z$ & -1.776 \\
\hline Asymp. Sig. (2-tailed) & .076 \\
\hline Exact Sig. [2*(1-tailed & $.095^{\mathrm{b}}$ \\
\hline Sig.)] & \\
\hline
\end{tabular}

Berdasarkan tabel variabel Non Performance Financing (NPF) diatas diperoleh nilai probabilitas signifikansi dapat dilihat hasil analisis Mann$0.347>0.05$ sehingga dapat disimpulkan Whitney test Bank Mega Syariah bahwa tidak terdapat perbedaan.

Tabel 17. Test Statistics $^{a}$ Bank Syariah Mandiri

\begin{tabular}{lr}
\hline & \multicolumn{2}{c}{ FDR } \\
\hline Mann-Whitney U & 4.000 \\
\hline Wilcoxon W & 19.000 \\
\hline Z & -1.776 \\
\hline Asymp. Sig. (2-tailed) & .076 \\
\hline
\end{tabular}


2018, Jurnal Tabarru' : Islamic Banking and Finance 1 (1) : 23 - 36

\begin{tabular}{l}
\hline Exact Sig. [2*(1-tailed $\quad .095^{\mathrm{b}}$ \\
Sig.)]
\end{tabular}

Berdasarkan tabel variabel diperoleh nilai probabilitas signifikansi Financing to Debt Ratio (FDR) diatas $0.076>0.05$ sehingga dapat disimpulkan dapat dilihat hasil analisis Mann- bahwa tidak terdapat perbedaan.

Whitney test Bank Syariah Mandiri

Tabel 18. Test Statistics ${ }^{a}$ Bank BRI Syariah

\begin{tabular}{lr}
\hline & FDR \\
\hline Mann-Whitney U & 7.000 \\
\hline Wilcoxon W & 22.000 \\
\hline Z & -1.149 \\
\hline Asymp. Sig. (2-tailed) & .251 \\
\hline Exact Sig. [2*(1-tailed & $.310^{\mathrm{b}}$ \\
Sig.)] & \\
\hline
\end{tabular}

Berdasarkan tabel variabel diperoleh nilai probabilitas signifikansi Financing to Debt Ratio (FDR) diatas $0.251>0.05$ sehingga dapat disimpulkan dapat dilihat hasil analisis Mann- bahwa tidak terdapat perbedaan.

Whitney test Bank BRI Syariah

\section{Tabel 19. Test Statistics ${ }^{a}$ Bank Mega Syariah}

\begin{tabular}{lr}
\hline & FDR \\
\hline Mann-Whitney U & 12.000 \\
\hline Wilcoxon W & 27.000 \\
\hline $\mathrm{Z}$ & -.104 \\
\hline Asymp. Sig. (2-tailed) & .917 \\
\hline $\begin{array}{l}\text { Exact Sig. [2*(1-tailed } \\
\text { Sig.)] }\end{array}$ & $1.000^{\mathrm{b}}$ \\
\hline
\end{tabular}

Berdasarkan tabel variabel diperoleh nilai probabilitas signifikansi Financing to Debt Ratio (FDR) diatas $0.917>0.05$ sehingga dapat disimpulkan dapat dilihat hasil analisis Mann- bahwa tidak terdapat perbedaan. Whitney test Bank Mega Syariah

Tabel 20. Rekapitulasi Uji Statistik

\begin{tabular}{lccc}
\hline \multicolumn{1}{c}{ RASIO } & $\begin{array}{c}\text { Sig. 2(tailed) } \\
\text { BANK SYARIAH } \\
\text { MANDIRI }\end{array}$ & $\begin{array}{c}\text { BANK BRI } \\
\text { SYARIAH }\end{array}$ & $\begin{array}{c}\text { BANK } \\
\text { MEGA } \\
\text { SYARIAH }\end{array}$ \\
\hline $\begin{array}{l}\text { Biaya Operasional Pendapatan } \\
\text { Operasional (BOPO) }\end{array}$ & 0.754 & 0.917 & 0.347 \\
\hline Dana Pihak Ketiga (DPK) & 0.009 & 0.009 & 0.009 \\
\hline
\end{tabular}


2018, Jurnal Tabarru' : Islamic Banking and Finance 1 (1) : 23 - 36

\begin{tabular}{llll}
\hline Non Performing Financing (NPF) & 0.076 & 0.347 & 0.076 \\
\hline Financing to Debt Ratio (FDR) & 0.076 & 0.251 & 0.917 \\
\hline
\end{tabular}

Dari tabel diatas dapat dilihat hasil dari perbandingan Pembiayaan Murabaha variabel Biaya Operasional Pendapatan Operasional (BOPO), Non Performing Financing (NPF) dan Financing to Debt Ratio (FDR) pada Bank Syariah Mandiri, Bank BRI Syariah dan Bank Mega Syariah tidak terdapat perbedaan. Hal ini dikarenakan standar dari probabilitas $>0.05$. Sedangkan Pembiayaan Murababa Varibel Dana Pihak Ketiga (DPK) pada Bank Syariah Mandiri, Bank BRI Syariah dan Bank Mega Syariah terdapat perbedaan. Hal ini dikarenakan standar dari probabilitas dari ketiga Bank tersebut $<0.05$.

\section{KESIMPULAN}

Dari hasil penelitian dan pembahasan yang telah diuraikan sebelumnya, maka dapat ditarik kesimpulan sebagai berikut:

1. Objek dalam penelitian ini adalah Bank Syariah Mandiri, Bank BRI Syariah dan Bank Mega Syariah.

2. Pembiayaan Murabaha Variabel Dana Pihak Ketiga (DPK) pada Bank Syariah Mandiri, Bank BRI Syariah dan Bank Mega Syariah terdapat perbedaan. Sedangkan Pembiayaan Murabaha variabel Biaya Operasional Pendapatan Operasional (BOPO), Non Performing Financing (NPF) dan Financing to Debt Ratio (FDR) tidak terdapat perbedaan.

\section{DAFTAR PUSTAKA}

Arifin, Z. 2002. Dasar-Dasar Manajemen Bank Syariah. Pustaka Al-Vabeth. Yoyakarta.

Agista, Aristantia Radis. 2015. Analisis Pengaruh DPK, CAR, NPF, dan ROA Terhadap Pembiayaan di
Bank Muamalat Indonesia. Tidak diterbitkan. FEB Universitas Muhammadiyah Surakarta. Surakarta.

Antonio, M Syafi I. 2003. Bank Syariah Dari Teori ke Praktek. PT Rajawali Press. Jakarta.

Antonio, Muhammad Syafìi. 2011. Bank Syariah dari Teori ke Praktik. Gema Insani Pers. Jakarta.

Dendawijaya, Lukman., 2005. Manajemen Perbankan. Ghalia Indonesia. Bogor.

Dendawijaya, Lukman. 2009. Manajemen Perbankan. Ghali Indonesia. Jakarta.

Karim, Adiwarman. 2004. Bank Islam: Analisis Fikih dan Keuangan. PT Raja Grafindo Persada, Jakarta.

Karim, Adiwarman. 2007. Bank Islam: Analisis Fiqih dan Keuangan. Raja Grafindo Persada. Jakarta.

Kasmir. 2012. Manajemen Perbankan. Edisi Revisi. Rajawali Pers. Jakarta.

Kasmir. 2013. Bank dan Lembaga Keuangan Lainnya. Rajawali Pers. Jakarta.

Latifatul, Mufidah. 2012. Analisis Variabel-variabel yang mempengaruhi Pembiayaan Murabahah pada Bank Umum Syariah. Tidak diterbitkan. FSH UIN Sunan Kalijaga. Yogyakarta.

Lifstin, Wardiantika. 2012. Pengaruh DPK, CAR, NPF dan SWBI Terhadap Pembiayaan Murabahah pada Bank Umum Syariah. Tidak diterbitkan. FE Universitas Negeri Surabaya. Surabaya.

Muhammad. 2005. Manajemen Bank Syariah. UPP AMP YKPN. Yogyakarta. 
Muhammad. 2008. Teknik Perhitungan Bagi Hasil dan Profit Margin pada Bank Syariah. UII Press. Yogyakarta.

Muklis, F. 2016. Struktur Kepemiliki, Ukuran Perusahaan dan Leverage, Al-Masraf: Jurnal Lembaga Keuangan dan Perbankan, 1 (2):245-255.

Muntoha, Ihsan. 2011. Pengaruh GDP, Inflasi dan Kebijakan Jenis Pembiayaan terhadap Rasio NPF. Tidak diterbitkan. FE UNDIP. Semarang.

Perwataatmadja, Karnaen dan Syafì i Antonio. 1999. Apa dan Bagaimana Bank Islam, cet ke-3. Dana Bhakti Wakaf. Yogyakarta.

Perwataatmadja, Karnaen A. 1999. Sistem Keuangan Islam. dalam majalah Pengembangan Perbankan Edisi No.75. Jakarta.

Rifai, Veithzal., 2007. Bank and Financial Institute Management. PT Raja Grafindo Persada. Jakarta.

Sagita, Maharani Devi. 2010. Analaisis Pengaruh CAR. NPF dan DPK Terhadap Penyaluran Pembiayaan (Studi Pada Bank Muamalat Indonesia Periode 2001-2009). Tidak diterbitkan. Universitas Diponegoro. Semarang. 